\title{
O “equilíbrio dinâmico” de Sólon: um breve ensaio
}

\author{
Carlos Eduardo de Souza Lima Gomes \\ FALE-UFMG \\ carloseduardogomes@gmail.com
}

\begin{abstract}
In the present work we intend to scrutinize some of Solon's compositions following one of his key questions: justice. Since it is a wide theme on his compositions, we focused our analysis on what we call "dynamical balance". To fulfill our goal on this essay, we present some of the author's biographical data and also what we can set as static and dynamical on his thought. At the end of our path, concealing all the information gathered, we try to outline the dynamicity of balance for Solon.

KEYWORDS: Solon; justice; archaic Greece; ancient Greek politics; "dynamical balance”.
\end{abstract}

Buscamos no presente artigo contemplar um ponto central das composições de Sólon: a questão da justiça. Por se tratar de um tema amplo e fulcral nos versos deste autor, ateremos nossa reflexão acerca daquilo que chamamos de "equilíbrio dinâmico", pensado pelo poeta. Para levar a cabo tal objetivo, num primeiro momento nós o apresentaremos, através dos dados biográficos que nos chegam; em seguida buscaremos, pautados pelos textos solonianos, o que seria estático ou dinâmico em sua visão cosmogônica; e, à guisa de conclusão, intentaremos esboçar o que seria, para o autor, a dinamicidade do equilíbrio, conciliando as informações coletadas ao longo do percurso.

\section{Sólon, o ateniense}

Dentre várias personalidades da Antiguidade, esta é uma das poucas a respeito das quais se podem apontar com alguma precisão vários dos seus dados biográficos; sobretudo devido ao fato de que muitas das dúvidas o próprio autor sana em seus versos. A própria origem do poeta nos é assim confirmada, conforme podemos verificar no seguinte excerto: "Antes fosse eu, pois, de Folegandros ou de Sícinos,/ e a pátria ateniense pela deles trocasse (...)."1

Sabendo a origem ateniense de Sólon, devemos traçar suas origens sociais. Ao que nos consta, este é oriundo de família nobre, pois, conforme nos afirma Delfim Leão:

\footnotetext{
${ }^{1}$ Cf. Sólon, F 2 W. Todos os fragmentos citados no presente trabalho são retirados de: Leão, D. F. Sólon: ética e política. Lisboa: Gulbenkian, 2001. As traduções apresentadas são também retiradas deste mesmo trabalho.
} 
(...) o mais sensato será efectivamente admitir que Sólon fazia parte da oligarquia aristocrática dominante, uma vez que ocupou o cargo de arconte, numa época em que essa magistratura estava dependente do nascimento e das posses. ${ }^{2}$

Continuando a biografia, temos que esse perfez uma série de viagens durante a juventude, quando teve a oportunidade de entrar em contato com diversas leituras de mundo, das mais diversas partes do Mundo grego ${ }^{3}$ e de fora dele. Isso é algo de grande monta a ser considerado quando pensamos no caráter diferenciado da visão soloniana no exercício de sua função legisladora, que certamente foi influenciada por esse conhecimento prévio de outras formas de pensar. Seguindo-se às viagens, temos o episódio da batalha por Salamina, valiosíssimo para o desenvolvimento econômico da Atenas de antanho e na ascensão do político Sólon na virada do século VII e VI a.C. ${ }^{4}$ É em momento imediatamente posterior que Sólon chega ao arcontado.

Temos, portanto, que, "Em meados da primeira década do séc. VI, Sólon congregava em si determinado número de características que faziam dele candidato natural à liderança política". 5 Essas características, arroladas rapidamente a partir da descrição apontada por Delfim Leão, seriam: nobreza, conhecimento da diversidade cultural, senso prático e a percepção da necessidade de se adaptar a legislação à realidade configurada. Sua ascensão após a batalha por Salamina e o seu destaque enquanto mediador em um episódio ligado a Delfos ${ }^{6}$ vêm somente adornar ainda mais seu curriculum. É desta forma que ele chega, em 594/593 ${ }^{7}$ ao arcontado em Atenas. A datação do nascimento do arconte é pautada pelo período de sua função política, pois se sabe que ele a exerceu com idade aproximada de quarenta anos. O que nos leva a colocar seu nascimento entre os anos de 635/ 630. Sua morte é consensualmente admitida entre 561/ 560, corroborando a ideia de que este teria falecido com idade

\footnotetext{
${ }^{2}$ Cf. Leão, D. F. Sólon: ética e política. Lisboa: Gulbenkian, 2001, p. 241.

${ }^{3}$ A expressão problemática utilizada, ou seja, Mundo grego, não quer implicar nenhuma referência a uma unidade que porventura teria existido entre esse ambiente multicultural que caracterizou a Grécia antiga. É antes uma comodidade que só a generalização permite, ao abarcar em um só termo todas as cidades que partilham da estrutura mínima da língua grega, tal como o elemento presente na oposição grego/ bárbaro. Contudo, sabemos da dificuldade e fragilidade dessa expressão, cabendo, portanto, a presente ressalva.

${ }^{4}$ Todas as datas, deste ponto em diante, deverão ser entendidas como a.C. (salvo indicações contrárias).

${ }^{5}$ Cf. Leão, op. cit., p. 268 (nota 2).

${ }^{6}$ Não detalharemos os pormenores do evento que em linhas gerais pode ser resumido como o reforço da preponderância do oráculo de Delfos no panorama religioso e político da época através de uma negociação que perpassou a Liga Anfitiônica, uma espécie de aliança militar que então existia.

${ }^{7}$ As poucas divergências a respeito da data do arcontado de Sólon não cabem ser expostas aqui dado o curto espaço do ensaio e não alterariam em nada o caráter informativo dos dados apresentados. Contudo, a alternativa ao arcontado em 594/ 593 é 592/ 591 - e uma terceira alternativa, menos acreditada, para 573/ 572 - o que não altera de forma significativa a exposição geral.
} 
bastante avançada, próxima dos oitenta anos. Normalmente se a apresenta como ocorrida no exterior, e suas cinzas teriam sido dispersas por Salamina, localidade que marcou a vida deste ateniense.

Foi na primeira década do século VI que Sólon efetua as reformas legislativas que conferiram algum equilíbrio às tensões existentes em Atenas. Essas tensões se davam, grosso modo, pelo choque dos interesses da aristocracia detentora do poder e da camada mais baixa da população, que se encontrava cada vez mais oprimida, dado o fato de a escravidão por dívidas ser instrumento válido na legislação ateniense. Esse equilíbrio é, sem dúvida, elemento assaz importante na reforma soloniana. Antes de o alcançarmos, procuremos perceber de que forma o poeta apresenta o que é estático e o que é dinâmico em sua composição.

\section{O estático e o dinâmico nas composições solonianas}

Sólon não apresenta em seus versos as palavras estático e dinâmico propriamente ditas. Porém, estas podem ser colhidas como concepções pertinentes ao seu pensamento, sobretudo, ligadas à mutabilidade e a imutabilidade das coisas. Para granjear respaldo à afirmativa, busquemos agora quais seriam os limites dessa imutabilidade.

O caráter imutável para o legislador está associado aos limites do divino, como é comum para o pensamento do período. Já em Hesíodo (meados do século VII) o panteão grego estava assim configurado. Ainda que seja possível argumentar que há a disputa dinâmica pelo poder na Teogonia de Hesíodo, ${ }^{8}$ com a sucessão entre Urano, Cronos e Zeus, esse último instaura a permanência ao eliminar a figura que o sucederia ao gerar, de si mesmo, Atena. ${ }^{9}$ O próprio elemento simbólico de Zeus ter suplantado o tempo (Cronos) é fator que ratifica a hipótese de que o domínio dos deuses é perene.

Diversas são as passagens nas quais Sólon fortalece esse pensamento; mas três em especial são significativas quando tomadas em conjunto, pois nos fornecem um escopo, ainda que indireto, dessa permanência através da chave do pensamento:

\footnotetext{
${ }^{8}$ São várias as edições acessíveis da Teogonia de Hesíodo, sugerimos edição de Jaa Torrano por se tratar de uma boa edição em língua portuguesa amplamente divulgada (cf. Hesíodo. Teogonia. A origem dos deuses. Tradução e estudo por Jaa Torrano. São Paulo: Iluminuras, 2003).

${ }^{9}$ Segundo o relato mitológico, Zeus seria sucedido pelo filho(a) que este teria com Métis (Astúcia); para evitar tal acontecimento, Zeus engole Métis e, em seguida, abre sua própria cabeça e tira de dentro dela a já totalmente constituída Atena. Esse "golpe" no devir instaura sua permanência no poder (cf. Hesíodo, Teogonia, 886-900).
} 
Não é feliz nenhum dos homens, mas antes uns desventurados todos os mortais que, do alto, o sol contempla. ${ }^{10}$

É insondável e muito difícil de apreender do seu intelecto a medida, que, sozinha, de todas as coisas o fim detém ${ }^{11}$

em tudo, é o pensamento dos imortais insondável para os homens. ${ }^{12}$

Facilmente perceptível, não há referência direta à imutabilidade defendida para o domínio divino; de que forma podem ser essas passagens significativas para caracterizar essa esfera como imutável? A percepção deste aspecto se dá de forma indireta, ao concatenarmos a ideia de que aos homens, desafortunados, não é possível auspiciar o pensamento dos imortais, insondável. Esse pensamento está intimamente ligado ao "sonoro julgamento" (sound judgement ${ }^{13}$ ) por seu "epíteto" insondável. No texto original, essa ligação se faz ainda maior, pois temos para o F $16 \mathrm{~W}$ vō̄o (medida do pensamento, em uma tradução mais literal) e para o F $17 \mathrm{~W}$ áфavìs vóos (pensamento insondável). Ainda que de forma discreta, temos a clara referência a um elemento de estabilidade e permanência dado através desse pensamento (vóos), que é o

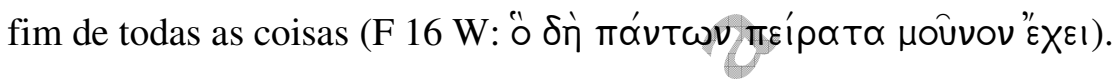

Uma vez configurados como senhores dessa perenidade, os deuses parecem, em vários momentos, deter a capacidade de dar ou retirar o movimento. É impossível não associar a tal pensamento um certo juízo de valor implícito; sendo o imutável, o permanente, da esfera do divino, há que se concluir que o movimento não é algo desejável, prezando-se sempre pela permanência, conforme esperamos que poderá ser confirmado adiante.

No F 4 W observamos os seguintes dizeres:

A nossa cidade, porém, jamais há-de ser destruída pelo decreto de Zeus/ e pelo arbítrio dos bem-aventurados deuses imortais,/ pois tão magnânima é a guardiã, filha de poderoso pai. (... $)^{14}$

\footnotetext{
${ }^{10}$ Cf. Sólon, F $14 \mathrm{~W}$.

${ }^{11}$ Cf. Sólon, F $16 \mathrm{~W}$.

${ }^{12}$ Cf. Sólon, F 17 W.

${ }^{13}$ Tal como estabelece Edmonds no F 16 de sua tradução em: Greek elegy and iambus. Being the remains of all the Greek elegiac and iambic poets from Callinus to Crates, excepting the choliambic writers, with the Anacreonta. Edited and translated by J. M. Edmonds. London/ New York: W. Heinemann/ Putman, 1931 (2 vol.).

${ }^{14}$ Cf. Sólon, F 4 W.
} 
Na passagem acima referida, temos a presença do elemento do destino, que é, notadamente, domínio dos mortais. Não há possibilidade de destino aos imortais por alguns aspectos: como o próprio excerto assegura, o destino é fruto da vontade dos deuses e não soberano a eles; além disso, o destino traz as mudanças para bem ou para mal, mas ainda sim mudança - elemento que não está presente na permanente esfera dos Numes.

Cabe somente aos homens a alternância, a incerteza dos caminhos da vida. Exatamente por tal aspecto que esses, retomando $\mathrm{F} 14 \mathrm{~W}$, consideram-se desventurados todos os mortais que, do alto, o sol contempla. Tal variabilidade, característica da vida dos homens, é-nos reafirmada na longa passagem sobre os dez períodos de sete anos da vida humana (F $27 \mathrm{~W}$ ), que, pela própria divisão em períodos, indica haver remodelações dos atributos a cada etapa da caminhada. E, ao final da jornada, percebese que os homens estão submetidos ao destino, ${ }^{15}$ limite dos deuses, tal como já explicitado.

Mas, uma vez que essa mudança os caracteriza e é dotada de um caráter negativo, há para o homem alguma esperança? Algum consolo?

Podemos crer que sim, resta algo que os acalente. O traço reconfortante mais óbvio, retirado do trabalho de Sólon é o do aprendizado (tal como ele próprio pode experimentar: sua vivência abriu possibilidades políticas a princípio não necessariamente estabelecidas por ele, como já apresentadas anteriormente). No F 18 W temos: "envelheço, sempre muitas coisas aprendendo". ${ }^{16}$ Isso é dito como algo benéfico, como se o aprendizado, e, conseguintemente, a sabedoria fosse a face boa da moeda da velhice. Não nos esqueçamos, também, de que, embora o "conhecimento dos imortais seja insondável aos homens", o aprendizado acaba por assegurar uma espécie de aproximação dessas duas esferas.

O outro traço que apazigua as "mazelas" da vida é o equilíbrio, traduzido na retidão das ações. Os homens seriam capazes de alcançar esse equilíbrio através de atos justos, não desmedidos. Isso pode ser captado em várias passagens, mas há uma que é preponderante nesse aspecto.

(...) Riquezas desejo possuir, mas adquiri-las injustamente/ não pretendo: sempre, a seguir, vem a justiça./ A fortuna que os deuses

\footnotetext{
${ }^{15}$ Cf. Sólon, F $27 \mathrm{~W}$ : (...) Se algúem alcançar o décimo e dele preencher a medida,/ não será fora de sazão, se lhe chegar a hora da morte.

${ }^{16}$ Cf. Sólon, F $18 \mathrm{~W}$.
} 
dão fica ao lado do homem,/ firme, desde os alicerces à cumeeira./ Porém, a que os homens honram, com insolência, a ordem devida/ não segue, mas levada por injustas ações,/ contrafeita vem atrás e, lesta, se lhe junta a perdição. (....). ${ }^{17}$

Visível se faz no excerto a busca pela riqueza. Essa busca é altamente compreensível, levando-se em conta os ideais aristocráticos que vigoravam. É certo que esses, cada vez mais, eram questionados pela sociedade. Contudo, ainda tinham força suficiente para perdurar. Isso não exclui a crítica presente, que nos leva a crer: maior que a riqueza é a conduta justa do homem. Pois a verdadeira prosperidade que essa riqueza traria não é possível de ser alcançada caso o homem execute ações e julgamentos injustos; a retidão deve ser sempre a bússola que orienta o homem nessa senda.

Acreditamos ser possível inferir que esse equilíbrio almejado pelo homem é, na verdade, uma tentativa de transformar sua realidade, de algo mutável, para imutável. Ainda que saibam os homens que, de princípio, os esforços para perenizar sua esfera estão fadados ao fracasso, cabe a esses a possibilidade de tentar amenizar os vieses da vida; para Sólon, em nossa leitura, tal equilíbrio é dado de forma dinâmica.

\section{O equilíbrio dinâmico de Sólon}

Se "equilíbrio", normalmente, remete-nos à ideia de falta de movimento e "dinâmico" à de modificação contínua, como podem estar concatenadas as duas acepções? Essa incoerência, que salta aos olhos em uma primeira leitura, é abrandada na medida em que nos aprofundamos no pensamento soloniano. Esperamos, no presente momento, já ter sido demonstrado, de maneira satisfatória, que o objetivo último do autor é esse equilíbrio, criando uma espécie de simulacro do divino na esfera dos homens. Investiguemos, agora, o que há de dinâmico nesse equilíbrio.

A dinâmica está implícita na medida em que exige do homem uma movimentação nesse sentido, ou seja, deve haver a intenção de se alcançar tal "meiotermo". Segundo Werner Jaeger:

É evidente que Sólon pressupõe uma conexão legal de causa e efeito entre os fenômenos da natureza e estabelece expressamente uma legalidade paralela nos acontecimentos sociais, quando em outra passagem diz: A chuva e o granizo vêm das nuvens, ao relâmpago

${ }^{17}$ Cf. Sólon, F 13 W. 
segue-se necessariamente o trovão, a cidade sucumbirá ante homens poderosos e o demos cairá nas mãos do ditador. ${ }^{18}$

O que há de inovador no pensamento de Sólon é a possibilidade de o homem interferir nessa relação de causa e consequência, não mais culpando os deuses por tudo o que lhe acontece. Ainda de acordo com Jaeger: "O conhecimento universal de uma legalidade política dos homens acarreta um dever de ação. O mundo em que Sólon vive já não deixa ao arbítrio dos deuses a extensão que lhe deixavam as crenças da Ilíada”. ${ }^{9}$ Mesmo que continue, conforme visto, bastante amplo o campo de ação que os deuses donos de amplo conhecimento e senhores do destino - detêm. Prosseguindo em sua explanação, o pensamento soloniano, para Jaeger:

Em vez de se limitar a soltar resignados lamentos sobre o destino do Homem e sua inexorabilidade, como os líricos jônicos de seu tempo, que com não menos profundidade sentiram o problema da dor no mundo, Sólon dirige aos homens um apelo para ganharem consciência da responsabilidade na ação e com a sua conduta política e moral oferece um modelo deste tipo de ação, vigoroso testemunho da inesgotável força vital e da seriedade ética do caráter ático. ${ }^{20}$

Esse testemunho evocado por Jaeger teria sido protagonizado pelo próprio Sólon, em pôr sua ação no sentido de trazer o equilíbrio e, assim, furtar-se a, simplesmente, creditar os infortúnios na conta dos deuses. Comentando a respeito de sua ação como magistrado, temos no F 5 o legislador que diz:

Ao povo dei então tal distinção, tanta quanto suficiente, honra não tomando e não acrescentando; aos que detinham poder e riquezas, admiráveis, à eles nada vexatório impus: pois de pé sustive forte escudo sobre ambos lados, a vitória não permitindo a nenhum de forma injusta. ${ }^{21}$

${ }^{18}$ Cf. Jaeger, W. Paideia. A formação do homem grego. Tradução de Artur M. Parreira. São Paulo: Martins Fontes, 1995, p. 180. A passagem do texto soloniano citada por Jaeger é parte integrante do F 9 W, em que lemos: Da nuvem parte a fúria da neve e do granizo/ e o trovão se gera do brilhante relâmpago;/ à conta de homens poderosos, a cidade se arruína e o povo,/ por ignorância, na servidão de um só governante caiu./ Ao que muito se exalçou fácil não sera conter,/ mais tarde; é agora que importa em tudo bem refletir.

${ }^{19}$ Cf. Jaeger, op. cit., p. 182.

${ }^{20}$ Cf. Jaeger, op. cit., p. 182.

${ }^{21} \mathrm{Cf}$. Sólon, F $5 \mathrm{~W}$ : Ao povo, portanto, concede privilégio bastantel e honra não lhe retirei nem acrescentei;/ aos que detinham a força e as riquezas granjeavam respeito,/ também a esses garanti que nenhuma afronta sofressem./ De pé, lancei um escudo sobre ambos:/vencer com injustiça, não o permiti, a nenhum deles. 


\section{nuntius antiquus}

É, portanto, baseados nesses aspectos que sugerimos ser Sólon defensor de um “equilíbrio dinâmico" para a solução das intempéries que acontecem ou são ocasionadas aos homens no correr de suas vidas. É a dinamicidade da ação e a aparente "estaticidade" do equilíbrio que constituem o par da difícil concatenação pretendida pelo autor em questão. E ele sabe da dificuldade de sua tarefa: "em questões importantes, a todos agradar é difícil". ${ }^{22}$ Mas, pela repercussão de suas ações, acreditamos ter sido ele recompensado pela boa reputação alcançada e pelo reconhecimento da inovação de seu pensamento no panorama de outrora. De forma sintética, podemos pensar que o sistema de "equilíbrio dinâmico" obtido do pensamento soloniano assemelha-se - para tomar uma metáfora da física de, cujo campo foram apreendidos os termos estático e dinâmico - a um sistema fechado, no qual pode haver interações internas, pequenas modificações, sendo que, ao final, a resultante de suas forças deve sempre ser nula. É uma forma de equilíbrio arriscada, mas capaz de conter, em sua miríade de possibilidades, os diversos aspectos da vida humana e das metamorfoses naturais do pensamento no correr dos anos de uma sociedade. Esperamos, ainda, que as trilhas panoramicamente atravessadas no espaço deste ensaio possam permitir novos aportes e posteriores desenvolyimentos, a fim de que compreendamos melhor o pensamento desse importante pensador político da Atenas arcaica.

\section{Referências}

BAILLY, A. Dictionnaire grec-français. Paris: Hachette, 2000.

BENJAMIN, W. Obras escolhidas I. Magia e técnica, arte e política: ensaios sobre literatura e história da cultura. Tradução de Sérgio Rouanet. São Paulo: Brasiliense, 1987.

CORVISIER, J.-N. Les grecs à la période archaïque (milieu du IX $\mathrm{X}^{\mathrm{e}}$ siècle à $478 \mathrm{av}$. J.C.). Paris: Ellipses, 1996.

Greek elegy and iambus. Being the remains of all the Greek elegiac and iambic poets from Callinus to Crates, excepting the choliambic writers, with the Anacreonta. Edited and translated by J. M. Edmonds. London/ New York: W. Heinemann/ Putman, 1931 (2 vol.).

${ }^{22}$ Cf. Sólon, F 7 W. 


\section{nuntius antiquus}

HESÍODO. Teogonia. A origem dos deuses. Tradução e estudo por Jaa Torrano. São Paulo: Iluminuras, 2003.

JAEGER, W. Paideia. A formação do homem grego. Tradução de Artur M. Parreira. São Paulo: Martins Fontes, 1995.

LEÃO, D. F. Sólon: ética e política. Lisboa: Gulbenkian, 2001.

MOSSÉ, C. A Grécia arcaica de Homero a Ésquilo: séculos VIII-VI a.C. Lisboa: Edições 70, 1989.

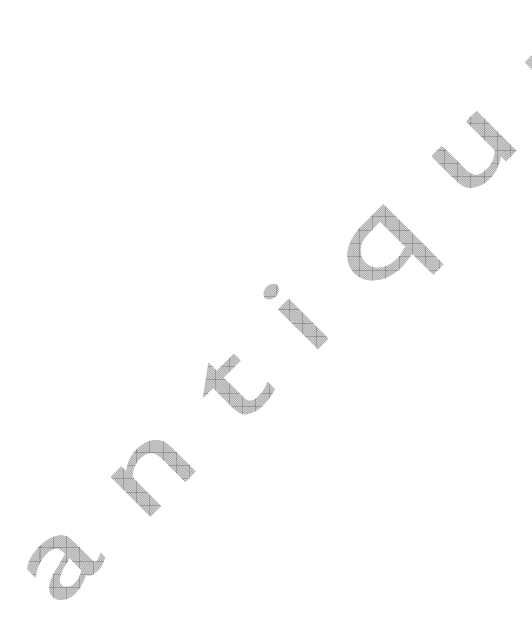

